Faculdade de Ciências Econômicas UFRGS
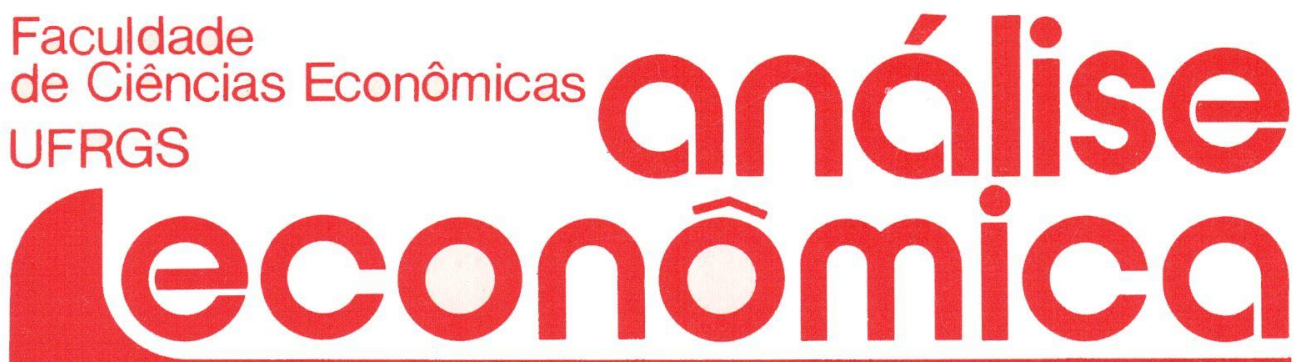

nesta edição:

- PRODUÇÃO DE ÁLCOOL E EMPREGO Otto G. Konzen e Juvir L. Mattuella

- NECESSIDADE DE PENSAR E CONSTRUIR O PÓS-CRISE Marcus Vinicius Pratini de Moraes

- CONTAS EXTERNAS

Fernando Ferrari Filho

- FETICHISMO

Leda Maria Paulani

- CRISE DO CAPITALISMO MUNDIAL Beki Morón de Macadar

- EXPANSÃO CAFEEIRA NO ESPÍRITO SANTO José L. Celin
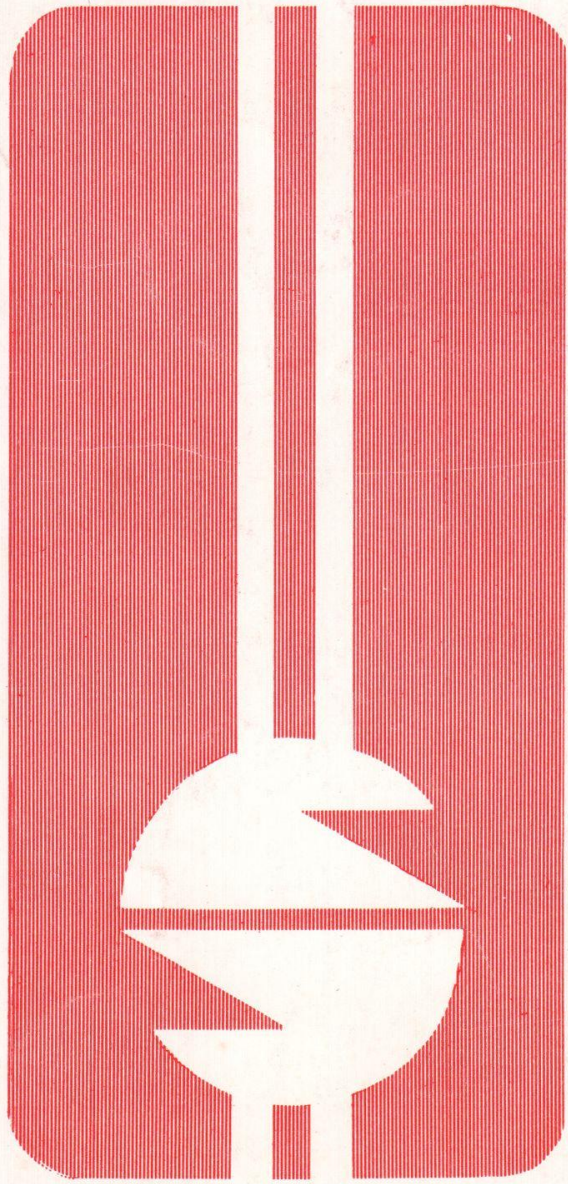
DIRETOR DA FACULDADE DE CIÉNCIAS ECONOMMICAS:

Prof. Antonio Carlos Santos Rosa/Prof. Edgar Irio Simm

VICE-DIRETOR:Prof. Nelson Rokembach/Prof. Walter Meucci Nique

CHEFE DO DEPARTAMENTO DE CIẼNCIAS ECONÔMICAS:

Prof. Renato Batista Masina

CONSElHo EdITORIAL: Prof. Pedro Cezar Dutra Fonseca (Presidente)

Prof. Achyles Barcelos da Costa

Prof. Carlos Augusto Crusius

Prof. Claudio Francisco Accurso

Prof. Edgar Augusto Lanzer

Prof. Ernani Hickmann

Prof. Nali de Jesus de Souza

Prof. Nuno Renan Lu de Figueiredo Pinto

Profa Otilia Beatriz Kroeff Carrion

Prof. Roberto Camps Moraes

Profạ Yeda Rorato Crusius

FUNDADOR: Prof. Antonio Carlos Santos Rosa

ANALISE ECONÔMICA publica dois números anuais, nos meses de março e novembro. O preço da așsinatura para 1985 é $\mathrm{Cr} \$ 6.000,00$, a ser pago através de cheque nominal para "Faculdade de Ciências Econômicas - UFRGS". Aceita-se permuta com revistas congêneres. Aceitam-se, também, livros para elaboração de resenhas ou recensões.

Toda a correspondência, material para publicação, assinaturas e permutas devem ser dirigidas a:

Prof. PEDRO CEZAR DUTRA FONSECA

Revista Análise Econômica

Avenida João Pessoa, $52-3 \%$ andar

90.000 - Porto Alegre (RS) - Brasil 


\section{AINDA SOBRE A QUESTÃO DAS CONTAS EXTERNAS*}

FERNANDO FERRARI FILHO* *

\section{INTRODUÇĀO}

Ao longo dos últimos anos, especialmente a partir de 1980, a situação do balanço de pagamentos tem sido apontada pelas autoridades monetárias como o principal aspecto da atual crise que atravessa a economia brasileira, ${ }^{1}$ pois os desequilíbrios nas contas externas agravam a crise cambial e, conseqüentemente, comprometem o próprio controle da dívida externa.

Nesse sentido, as medidas de política econômica adotadas com o beneplácito do Fundo Monetário Internacional, devido aos empréstimos de "socorro" concedidos por essa instituição, têm se consubstanciado em políticas de ajustamento imediato dos desequilíbrios estruturais do balanço de pagamentos através da obtenção de sucessivos superávits comerciais crescentes. Estes, por sua

\footnotetext{
*Entregue para publicação em 28/09/1984.

* Mestre em Economia pelo Curso de Pós-Graduação em Economia do Centro de Estu. dos e Pesquisas Econômicas da UFRGS. O autor gostaria de agradecer às críticas e sugestões apresentadas pelo Prof. Pedro Cesar Dutra Fonseca.

1 - Para tanto, os discursos oficiais das autoridades monetárias dizem respeito ao fato de que os desequilibrios observados no balanço de pagamentos são decorrentes tanto do aumento dos preços do petróleo, verificado em fins de 1973 e em 1979, quanto da elevação das taxas de juros internacionais a partir principalmente de 1980, como resultado da política econômica norte-americana de gestão do orçamento fiscal através do supply side economics e da rigidez do controle da oferta monetária.
}

$$
\text { ANÁLISE ECONOOMICA }
$$$$
\text { ANO } 2
$$

N? 4 NOV./1984 
vez, provocam quedas nos níveis de emprego e produto, bem como elevação nos níveis de preços da economia, na medida em que o direcionamento e a concentração dos esforços de uma política econômica voltada para o setor externo são incompatíveis com uma política econômica de desenvolvimento interno da economia.

Diante dos reflexos de crise da economia brasileira, o presente artigo pretende enfatizar que as políticas de estabilização a curto prazo para solucionar os problemas de estrangulamento externo não têm surtido efeito esperado, e tão-somente vêm agravando as questões do ponto de vista social e de reordenação da economia.

Para tanto, o artigo se divide em três partes: na primeira, apresenta-se um breve comentário sobre as formas de dependência externa, e em particular o caso da economia brasileira; na segunda parte, realiza-se uma investigação sobre a evolução das principais contas externas brasileiras; finalmente, na terceira parte, tenta-se, com base nas observações anteriores, mostrar que a reorientação da política econômica se constitui na única maneira de solucionar os atuais problemas econômico-sociais brasileiros, bem como resguardar a soberania política do País.

\section{DEPENDÊNCIA EXTERNA}

As questões sobre dependência econômica desenvolvidas a seguir são resultado do trabalho "Dependência Externa e Moratória", realizado e apresentado pelo Grupo de Estudos da Sociedade de Économia do Rio Grande do Sul, ${ }^{2}$ no 5 Q Congresso Brasileiro de Economistas de Curitiba, em novembro de 1983.

Naquela ocasião, o trabalho identificou três formas de dependência econômica: a dependência por insuficiência de poupança real; a dependência por insuficiência de poder de compra externo, caracterizado pelo chamado "hiato de recursos"; e a dependência representada pelo custo financeiro acumulado da dívida externa.

Passemos, pois, à análise individual de cada aspecto de dependência para, a partir daí, observar em qual șituação se insere o Brasil.

2 - O grupo estava composto por Adoni Alencar, Fernando Ferrari Filho, Hélio Henkin, Maria Cristina Severo, Renato Henz, Teresinha Fialho e Vera Schneider. 


\section{INSUFICIÊNCIA DE POUPANÇA REAL}

A insuficiência de poupança real interna é a principal razão alegada para que o Pais busque recursos externos, seja por investimentos diretos, seja sob a forma de empréstimos e financiamentos.

A questão a ser colocada diz respeito ao fato de que a função deste capital como fonte de poupança adicional verifica-se somente quando o sistema, operando à plena capacidade, encontra dificuldades para reduzir o nivel de consumo e, conseqüentemente, gerar um determinado nível de poupança.

Se no Brasil observa-se, em certos períodos, a existência de recursos ociosos, então provavelmente poderia haver geração do produto sem que fosse necessária a poupança externa. Por outro lado, essa capacidade ociosa dominante na economia brasileira nos últimos anos mostra que o que existe é suficiência e, também, excesso de poupança real não utilizada.

Diante disso, parece que, no caso brasileiro, o capital externo tem como função a cumprir não o de gerar poupança, mas sim ser supridor de divisas necessárias aos ajustamentos do balanço de pagamentos.

Deve-se ainda observar que, se houver um plano de investimentos com redistribuição de renda e redinamização da estrutura de oferta, a questão da dependência por poupança externa fica consideravelmente colocada em segundo plano.

\section{DEPENDENCIA DE BENS E SERVIC̣OS}

No que diz respeito à dependência de bens e serviços, devese observar o "hiato de recursos"3 que caracteriza a defasagem existente entre a oferta interna de bens e serviços, dada pela tecnologia, e a demanda interna da economia.

Essa defasagem que, por sua vez, reflete a incapacidade de um país transformar capacidade de compra interna em poder de compra externa pode ser amenizada através das políticas de protecionismo, fomento às exportações e restrições às importações, especificamente as consideradas supérfluas e que não freiem o ritmo de expansão do processo produtivo, bem como pela melhora na relação dos termos de troca internacionais.

3 - Aqui definido como o déficit em transações correntes menos os serviços não-produtivos. 
No Brasil, o discurso oficial das autoridades monetárias, como foi colocado anteriormente, parte do ponto de vista de que os "choques" externos provenientes fundamentalmente das elevações dos preços do petróleo foram determinantes básicos para a contribuição do "hiato de recursos".

Entretanto, deve-se deixar claro que a polftica de endividamento brasileiro é anterior aos choques externos, já que se originou nos anos 1967/1968. Por outro lado, percebe-se que os resultados da política econômica estabelecidas pelo Governo ao longo dos anos 1980 reduzem substancialmente as questões de restrições tecnológicas apresentadas pelo "hiato de recursos".

Portanto, parece-nos que o argumento de que a dependência brasileira caracteriza-se pela dependência de bens e serviços é falacioso, à medida em que se analisem as questões acima apresentadas.

\section{DEPENDENCIA FINANCEIRA}

A dependência externa sob a ótica financeira refere-se basicamente ao pagamento do serviço da dívida externa, principalmente no seu componente dinâmico que vem a ser a necessidade do pagamento de juros.

A política de crescimento com endividamento realizada pelo Brasil durante o período denominado "milagre brasileiro", 1968 a 1973, fez com que o País se tornasse dependente do sistema financeiro internacional que, por sua vez, buscava, naquela época, saida para a sua liquidez excessiva através de empréstimos a países do Terceiro Mundo.

Esta situação de dependência agrava-se a partir de 1980, devido à elevação dos juros internacionais, fazendo com que estes ultrapassem, em valor absoluto, as amortizações.

Como decorrência de tal situação, tem-se uma grande dificuldade de manobra com a dívida externa, à medida em que os credores exercem pressão mais forte sobre o pagamento dos juros.

Por conseguinte, desencadeia-se a crise cambial nos anos 1980 e, conseqüentemente, a própria inadimplência da economia brasileira.

A partir da aceitação de que a dependência econômica brasileira caracteriza-se pela dependência financeira, passemos a investigar as principais contas do setor externo da economia brasileira. 


\section{ANÁL.ISE DO SETOR EXTERNO}

No que diz respeito à balança comercial, o esforço de ajustamento tem se baseado fundamentalmente na contenção das importações, o que é feito basicamente por meio de uma contração da demanda agregada através de políticas monetária e fiscal restritivas, e de fomento às exportações a partir dos incentivos fiscais concedidos pelo Governo.

$O$ resultado da conjugação de tais esforços pode ser visto na Tabela 1 abaixo:

TABELA 1 - EVOLUÇĀo DA BALANÇA COMERCIAL DO BRASIL: 1981/1984

(US $\$$ bilhões)

\begin{tabular}{l|r|r|r|r}
\hline & 1981 & 1982 & 1983 & $1984^{1}$ \\
\hline Saldo & 1,2 & 0,8 & 6,5 & 11,5 \\
Exportação & 23,3 & 20,2 & 21,9 & 25,5 \\
Importação & 22,1 & 19,4 & 15,4 & 14,0 \\
\hline
\end{tabular}

1 - Estimativas do autor a partir do comportamento da balança comercial nos 6 (seis) primeiros meses de 1984.

Fonte: Banco Central do Brasil - Relatórios Anuais de 1982 e 1983.

Conforme se observa na tabela acima, há, entre 1981 e 1984 , uma redução drástica no volume das importações, a preços correntes, da ordem de $36 \%$, ao passo que, mesmo com o crescimento significativo de cerca de 16\% registrado entre os anos de 1983 e 1984, tem-se somente um crescimento no volume das exportações, também a preços correntes, da ordem de $9,4 \%$, durante o período de 1981 a 1984.

Apesar desta evolução favorável da balança comercial, o País ainda não consegue atingir as suas metas de ajustes esperados, pois há previsões econômicas anunciando novas elevações das taxas de juros internacionais a curto prazo, bem como uma tendência acentuada à elevação para os próximos anos.

Por outro lado, o fato de as autoridades monetárias ainda não terem alcançado seus objetivos, por mais que continuem aumentando o excesso de produção sobre o dispêndio total, pode ser explicado pela evolução do pagamento do serviço da dívida que tem como ponto central a questão dos juros financeiros, conforme concluído anteriormente, que oneram o déficit em transações correntes a partir da conta serviços não-fatores. 
A evolução do pagamento do serviço da dívida externa pode ser observada na Tabela 2 a seguir:

TABELA 2 - EVOLUÇÃO DO SERVIÇO DA DIVIDA EXTERNA DO BRASIL: $1981 / 1984$ (US $\$$ bilhões)

\begin{tabular}{l|c|c|c|c}
\hline & 1981 & 1982 & 1983 & 1984 \\
\hline Total & 15,4 & 18,3 & 18,5 & 20,9 \\
Juros & 9,2 & 11,4 & 9,6 & 11,4 \\
Amortizações & 6,2 & 6,9 & 8,9 & 9,5 \\
\hline
\end{tabular}

1 - Estimativas do autor com base numa taxa de juros média, ponderada pelas Prime rate e $L$ ibor, da ordem de $12,5 \%$ a.a.

Fonte: Banco Central do Brasil - Relatórios Anuais de 1982 e 1983.

Analisando-se a Tabela 2, percebe-se que ocorre um crescimento do serviço da divida externa de cerca de 35,7\%, entre 1981 e 1984, constituído pelos crescimentos dos juros da ordem de $23,9 \%$, bem como das amortizações em torno de $53,2 \%$.

Porém, o agravante da questão diz respeito ao fato de que, mesmo com o imenso sacrifício realizado, principalmente ao longo de 1984, para se alcançar os superávits comerciais esperados, torna-se inócua a expectativa de solucionar a questão do estrangulamento externo, uma vez que o saldo positivo na balança comercial tão-somente vem cobrir as despesas de juros da dívida.

$O$ resultado deste hiato entre o saldo comercial e o pagamento do serviço da dívida deve, portanto, ser coberto pela captação de recursos externos, diretos e indiretos, através da conta movimento de capitais.

Os principais dados sobre captação de recursos externos da conta movimento de capitais estão apresentados na Tabela 3 :

TABELA 3 - EVOLUC̣ÃO DA CONTA MOVIMENTO DE CAPITAIS DO BRASIL: 1981/1984 (US\$ bilhões)

\begin{tabular}{l|r|r|r|r}
\hline & 1981 & 1982 & 1983 & $1984^{1}$ \\
\hline Investimento de risco & 2,3 & 2,5 & 1,3 & 0,5 \\
Empréstimos e financiamentos & 10,5 & 10,8 & 8,1 & 13,5 \\
\hline
\end{tabular}

1 - A expectativa do Governo é que entre em 1984 um montante de US\$14 bilhões na conta movimento de capitais para que o balanço de pagamentos se equilibre.

Fonte: Banco Central do Brasil - Relatórios Anuais de 1982 e 1983. 
Percebe-se por esta tabela que há uma redução acentuada no nível de investimentos diretos de cerca de 78,3\%, entre 1981 e 1984, devido, fundamentalmente, ao quadro de incerteza da situação econômica do Brasil. Por outro lado, observa-se também uma significativa elevação no nivel de empréstimos e financiamentos, por parte das instituições financeiras internacionais, da ordem de $28,6 \%$, necessários para fechar as contas do balanço de pagamentos.

Por fim, levando-se em consideração que a dívida externa forma-se pela entrada de capitais de empréstimos, ${ }^{4}$ tem-se o seguinte comportamento da dívida externa e das reservas brasileiras, conforme nos mostra a Tabela 4:

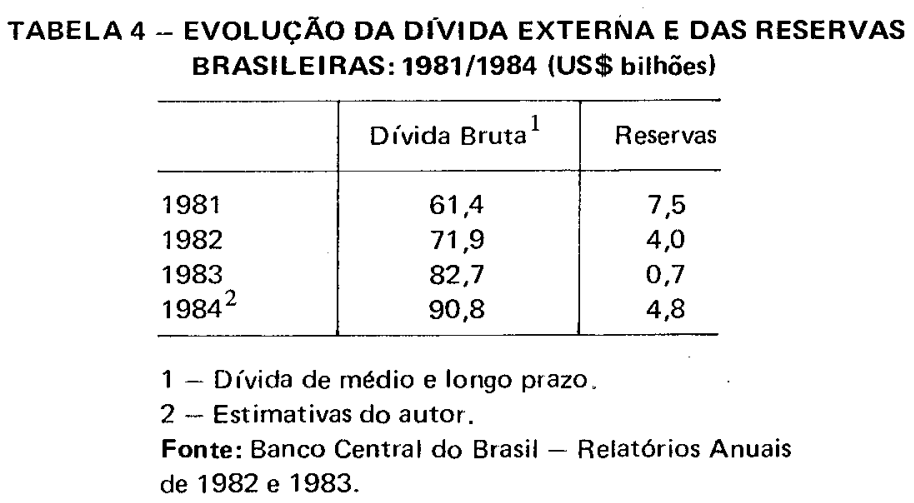

Analisando-se a tabela acima, percebe-se que a composição da dívida externa bruta cresce, entre 1981 e 1984, na ordem de 47,9\%, ao passo que, devido principalmente aos déficits globais no balanco de pagamentos, ${ }^{5}$ as reservas reduzem-se de um montante de US $\$ 7,5$ bilhões para US $\$ 4,8$ bilhões, ou seja, decrescem $56,3 \%$.

Portanto, mesmo que não se trate mais o Brasil como um País que gasta mais do que produz, segundo posicionamento dos principais credores internacionais, devido aos seus superávits comerciais,

4 - Se a entrada de capitais externos é maior que os saldos negativos em transações correntes, tem-se um saldo positivo no balanço de pagamentos e, conseqüentemente, um aumento nas reservas, ao passo que se a entrada de capitais externos é insuficiente para cobrir os saldos negativos em transações correntes, há necessidade de se buscar capitais com. pensatórios e/ou reduzir as reservas.

5 - Superávits ou déficits globais no balanço de pagamentos do Brasil: 1981 (US $\$ 0,6$ bilhões), 1982 (-US $\$ 8,8$ bilhões), 1983 (-US $\$ 5,7$ bilhões) e 1984 (previsão de US $\$ 2,0$ bilhões). 
nota-se que as tentativas de pagar as contas em dia são insuficientes para conter a aceleração da dívida externa. Esta situação, é óbvio, não pode perdurar e deve-se primordialmente alterar os termos de negociações da dívida externa.

\section{CONCLUSÕES}

Como ficou patente, percebe-se que a hipótese central de que o tratamento de choque constitui, segundo as Autoridades Monetárias, a única maneira de enfrentar o problema externo, na atual conjuntura, pode ser contestada pelo fato de que o método de geração de divisas e, conseqüentemente, aumento das reservas cambiais, não soluciona os problemas de curto prazo do balanço de pagamentos e tampouco ameniza o problema da dívida externa.

Por outro lado, como ficou evidenciado, se a questão dos desequilibrios do balanço de pagamentos está associada fundamentalmente ao problema financeiro, não se pode admitir que se continue propondo ao País um processo de ajustamento cujas variáveis sejam o aprofundamento da recessão, a desarticulação da estrutura produtiva e o desemprego crescente, acarretando o agravamento dos custos sociais e políticos.

Deve-se, portanto, esperar do próximo governo, a ser constituído a partir de março de 1985, a retomado do desenvolvimento econômico, isto é, reativação dos níveis de produção e emprego, compatíveis com as exigências sociais através de um "entendimento" com os credores internacionais no sentido de se obter redução nos juros e uma carência de longo prazo para as amortizações, bem como acentuar a necessidade de resgatar a soberania nacional através da não-aceitação da administração da nossa economia por parte do Fundo Monetário Internacional.

\section{BIBLIOGRAFIA}

1. Banco Central do Brasil. Re/atorios Anuais. 1982 (vol. 19/fev. 83) e 1983 (vol. 20/mar. ço 84 ).

2. Batista Jr., Paulo N. Mito e Realidade da D/vida Externa Brasileira. Paz e Terra.

3. Grupo de Estudos da Sociedade de Economia do RS. Divida Externa e Moratória. Mimeo. 